\title{
Graciliano Ramos da eSCravidão À Sedição
}

\author{
Fabio Cesar Alves \\ Universidade de São Paulo
}

Resumo

Palavras-chave:

Forma literária e processo

social;

O artigo pretende examinar, por meio de um excerto da obra Memórias do cárcere (1953), de Graciliano Ramos, o movimento composicional do livro, tendo como ponto de partida a reconstrução da experiência de cadeia por parte do narrador situado nos anos 1940 e 1950. Tal reconstrução the permite desnudar aspectos regressivos tanto da modernização brasileira quanto da política do Partido no qual o escritor militou.

\section{Abstract}

The article intends to examine, through an excerpt of the work Memórias do cárcere (1953), by Graciliano Ramos, the compositional movement of the book, having as a starting point the reconstruction of the narrator's experience in jail, during the 40's and 50's. Such reconstruction enables him to uncover regressive aspects of both the Brazilian modernization process and the politics of the Party in which the author advocated.

Graciliano

Ramos,

Memorialismo, Memórias do cárcere; modernização brasileira.

Key-words:

literary stile and social

process;

Graciliano

Ramos;

memorialist

writing;

Memórias do

cárcere;

brazilian

modernization. 


\title{
Um escritor no navio negreiro
}

\author{
$\mathrm{Ai}$, preto, que ris em mim, \\ nesta roupinha de luto \\ e nesta noite sem causa. \\ (Carlos Drummond de Andrade, "Canto negro")
}

Em Ficção e confissão, Antonio Candido ${ }^{1}$ analisa o conjunto da obra de Graciliano Ramos (1892-1953) a fim de compreender o percurso literário do escritor e a sua rotação para os textos autobiográficos a partir de 1945, com a publicação de Infância. Candido parte de considerações da crítica precedente (Álvaro Lins notara que as personagens de Graciliano viviam "voltadas para dentro" e Otto Maria Carpeaux assinalara a convergência de todos os elementos narrativos para a personagem principal) ${ }^{2}$, a fim de demonstrar como, desde a estreia com o romance Caetés, a confissão constituía uma tendência latente dos textos ficcionais. Assim a experiência, para Graciliano, se revelava como condição da escrita, e o traço confessional, adensando-se progressivamente, culminaria nas obras propriamente memorialísticas do autor, como Infância e Memórias do cárcere (1953), sem desconsiderar a sua incursão pela União Soviética que aparece relatada em Viagem (1954) - as duas últimas, obras publicadas postumamente.

Memórias do cárcere constitui uma recriação da experiência de prisão a partir da perspectiva do presente: Graciliano começa a redigir a obra em janeiro de 1946 e o processo de escritura se estende até o fim de sua vida. Como se sabe, o escritor foi detido em março de 1936 na cidade de Maceió e libertado onze meses depois. Conduzido ao Recife e enviado para o Rio de Janeiro a bordo do navio-presídio Manaus, passou temporadas na Casa de Detenção e na Colônia de Dois Rios, a temível prisão de criminosos comuns da Ilha Grande. Por isso, cada uma das partes das Memórias corresponde aos lugares nos quais o protagonista esteve encarcerado: "Viagens", "Pavilhão dos Primários", "Colônia Correcional" e "Casa de Correção".

Como característica inerente a todo texto memorialístico, trata-se de uma obra narrada não exatamente pelo sujeito empírico, mas por uma voz que, partindo dele, reconstrói o seu passado e deixa as marcas do presente da enunciação naquilo que é relembrado. Desse modo, o texto confessional pressupõe, como na ficção, a figuração da subjetividade, uma vez que comunica um passado reinterpretado pela perspectiva da atualidade (especialmente se pensarmos na decalagem temporal entre o momento da prisão de Graciliano e a iniciativa, propriamente dita, de recriá-la literariamente). Essa tradição de "escritas do eu", para empregar o termo cunhado por Georges Gusdorf ${ }^{3}$, tem larga precedência tanto na literatura ocidental quanto na brasileira.

De modo mais amplo, a origem do gênero deita raízes no exame de consciência religioso, em particular na autoinspeção sistemática promovida pelos cristãos protestantes. Segundo Weber, enquanto o fiel católico dispunha da graça sacramental da Igreja para expurgar seus pecados, ao calvinista era destinado viver permanentemente sob a tensão promovida pela culpa ${ }^{4}$. Por isso, com a ajuda de apontamentos pessoais, o cristão reformado "tomava o pulso" de si por meio de um virtuosístico processo de autotortura e reflexão 
metódica. Já despida, no século XVIII, do elemento religioso, a confissão encontraria a sua versão literária na variante profana do diário íntimo, nos textos epistolográficos e memorialísticos - desses últimos, o marco da produção moderna em prosa são as Confissões (1782), de J. J. Rosseau.

$\mathrm{Na}$ historiografia literária brasileira, a consolidação dos gêneros híbridos corresponde ao processo de formação da nossa literatura durante o projeto romântico: a imprensa carioca do século XIX permitiu o desenvolvimento do hebdomadário e do folhetim, que uniam boas doses de criatividade ao jornalismo. Obras seminais da memorialística brasileira estão em José de Alencar (Como e porque sou romancista, 1893) e Joaquim Nabuco (Minha formação, 1901) $)^{5}$ Tal quadro se ampliou com a produção dos modernistas da fase heroica e adensou-se com a "rotação memorialística" de Graciliano entre os anos 1940 e 1950.

No caso particular das Memórias do cárcere, a confissão do sujeito "à beira da cova" permite-lhe expor a própria intimidade e refletir, com certo distanciamento e a partir da fusão de temporalidades, sobre a experiência de prisão e a realidade brasileira dos anos 1930 . Entretanto, a recuperação do passado no momento da escritura é também uma resposta política do escritor situado em um novo contexto repressivo (o governo Dutra) e quando Graciliano Ramos já é militante do então Partido Comunista do Brasil (PCB), ao qual se filiara em 1945 a convite de Luís Carlos Prestes. Trata-se, portanto, do depoimento de um intelectual que toma distância de si e se vê como parte da cena política. Por isso, o fato de este sujeito, ao recriar sua experiência, ter de se haver com a herança patriarcal que nele subsiste garante à obra uma dimensão incomum, pelo seu poder de revelação quanto a questões irresolvidas tanto na esfera da subjetividade quanto na política.

A tradição das "confissões do inconfessável", ou o "exame de consciência ateu, com a coragem do desejo individual" é, segundo Roberto Schwarz, uma dimensão literária que falta à nossa cultura ${ }^{6}$. De fato, raros são os momentos da produção brasileira em prosa nos quais se verifica a autoinspeção sistemática, tal como a promovida pelo narrador das Memórias do cárcere. Em Machado de Assis, o autoexame é condicionado pelo cinismo do narrador que pertence às classes dominantes (Memorial de Aires). A respeito de Um homem sem profissão, de Oswald de Andrade, Antonio Candido alerta que "não se deve procurar na obra autoanálise nem retrato do tempo", mais disposta que está a esclarecer a "aventura lírica do Quixote entre o real e o sonho"7. Nesses modelos, bem como em peças importantes do memorialismo brasileiro, como Baú de ossos, de Pedro Nava, ou Navegação de cabotagem, de Jorge Amado, estamos distantes de um rigoroso exame de consciência tal como se verifica na obra de Graciliano. Neste caso, colabora para a disposição à autocrítica a cultura partidária moralmente rígida com a qual este intelectual lidou: as sessões de autocríticas do PCB, que viraram rotina especialmente a partir dos anos 1940, consistiam em angustiosas exposições públicas dos militantes, visando a uma autocorreção cujo desdobramento seria, teoricamente, a redefinição de rumos do Partido ${ }^{8}$.

Nas Memórias, o olhar de intervenção do narrador em relação ao presente, ao mesmo tempo que recupera o passado, desenha a sua fisionomia intelectual: o elemento que, para Lukács, garante a tipicidade dos grandes romances realistas ${ }^{9}$. Por outra, trata-se de um narrador típico que submete, pela reconstrução do passado, a sua experiência pessoal à discussão política. Do ponto de vista da composição, conjugam-se, no texto, o relato 
propriamente factual à reflexão, quando o fato suscita um movimento de retração do narrador e suas ponderações quanto ao que foi contado. Em "Viagens" (primeira parte das Memórias), há uma passagem que ilustra exemplarmente o arranjo descrito. No capítulo 10, o prisioneiro está no porão do Manaus, o navio que conduz os "elementos subversivos" para o Rio de Janeiro. O cenário aviltante - homens arqueados como trouxas, detritos e exibições da intimidade alheia - faz o detento permanecer desperto, fumando ininterruptamente, durante a primeira noite de viagem forçada. À luz do dia, ele procura reter a fisionomia dos companheiros e retomar os apontamentos de prisão que iniciara ainda no quartel de Recife. Desistindo da empresa, aproxima-se dos revolucionários de Natal:

\begin{abstract}
Os hábitos de classe me aproximaram do sujeito gordo e louro que fumava cachimbo, sentado na rede, a sorrir, do rapaz estrábico, de óculos. Importantes, um secretário da Fazenda, outro secretário do Interior, no governo revolucionário de Natal. Propriamente não fora governo, fora doidice: nisto, embrulhados, concordavam todos. Estavam ali dois figurões, dois responsáveis, dois criminosos, porque tinham sido pegados com o rabo na ratoeira. Não me arriscaria a dizer como se chamavam. Macedo e Lauro Lago. Isso, repetido com frequência, me permanecia na memória, mas se me dirigisse a qualquer deles, trocaria as designações. Falavam-me também num terceiro chefe da sedição, o mais importante, conservado em Natal por não se poder ainda locomover: seviciado em demasia, aguentara pancadas no rim e, meses depois da prisão, mijava sangue ${ }^{10}$.
\end{abstract}

O excerto se segue logo após o prisioneiro tomar conhecimento de que também viajavam no navio "vagabundos e ladrões", e por isso passa a esconder o dinheiro que trazia e a vigiar as suas roupas. Conscientemente, o narrador acusa os seus "hábitos de classe" como o motivo da proximidade com os líderes da insurreição: o "sujeito gordo e louro" e o "rapaz de óculos", pequeno-burgueses como ele, interessavam-lhe mais do que os gatunos, confissão que já indicia a disposição à autocrítica.

Essa proximidade com os líderes e com os bastidores da sedição permitem-lhe revelar os juízos dos próprios insurgentes em relação ao levante de 1935: "uma doidice". Tratava-se, do ponto de vista histórico, de um desdobramento tardio das revoltas tenentistas e, ao mesmo tempo, de um teste revolucionário em solo sulamericano encampado pela Internacional Comunista (IC $)^{11}$. O sentido hiperbolizado das sedições, porém, foi explorado pelo PCB durante muito tempo, o que permite afirmar que, se o prisioneiro já afrontava as interpretações triunfalistas sobre a insurreição, o narrador, ao recortar o fato, ratifica a crítica à direção do Partido em que milita ${ }^{12}$.

A gradação na referência aos companheiros ("figurões", "responsáveis", "criminosos") é significativa porque mostra o abismo para o qual o Estado repressor os empurrara: os líderes do levante de Natal tornaram-se autores de um crime. A explicação paradoxal, de que são criminosos porque foram pegos pela polícia de Vargas, enfatiza a encenação para capturá-los: a imagem da "ratoeira" associa o levante ao pretexto adequado para que as forças repressivas atuassem com toda a brutalidade, de maneira justificada aos olhos da opinião pública, contra os trabalhadores e os setores de esquerda. A sedição, pois, seria apenas o dispositivo capaz de respaldar a perseguição em massa que efetivamente acontecia em todo o país.

De fato, o contexto do ano de 1935 já era o da repressão desenfreada muito antes dos levantes de novembro, como resposta de Vargas às manifestações populares na luta contra o fascismo (no Brasil, ideais encampados pela Aliança Nacional Libertadora, a ANL) e, 
especialmente, à mobilização do movimento operário que exigia maior participação nas decisões políticas, materializada nas inúmeras greves dos anos anteriores. À criação da ANL, em março de 1935, o governo respondeu com a Lei de Segurança Nacional, de abril, que lhe conferia poderes especiais para reprimir atividades consideradas subversivas, além de proibir as organizações independentes de trabalhadores ${ }^{13}$. A formulação do narrador, então, dá conta da situação de terror e de perseguição perpetrada por Vargas, bem como os motivos da prisão: os insurgentes tornaram-se infratores porque, ao promoverem o motim, caíram na armadilha montada pelo Estado. Ou seja, ele percebe que a tocaia das forças repressivas estava preparada há muito ${ }^{14}$.

O narrador confessa, ainda, confundir na rememoração José Macedo e Lauro Lago e ter sabido da existência de um terceiro líder que, torturado, não pôde ser conduzido ao Rio de Janeiro $^{15}$. A sequência de imagens com que expõe o fato é bastante agressiva: "seviciado em demasia", "aguentara pancadas no rim" e "mijava sangue". O impactante léxico empregado realça a brutalidade dos fatos narrados, sem "envolvê-los em gaze ou contorná-los", como alertara o narrador na abertura do livro, e configura o perfil entrevisto por John Gledson, o do "ex-prisioneiro político ferozmente determinado a atirar a verdade cruel na cara dos leitores"16.

A sensação de choque, porém, não é exclusiva do leitor: o prisioneiro também é atingido pela revelação de fatos inesperados e, da perspectiva da composição, há uma inflexão na narrativa, que deixa de abordar a realidade exterior para focar a interioridade do sujeito. $\mathrm{O}$ conhecimento da tortura infligida aos líderes do levante, de que se aproxima o narrador na rememoração por meio da ambivalência de vozes e de temporalidades, permite-lhe analisar, de maneira aguda e se valendo da própria experiência, a violência estrutural do país:

\begin{abstract}
Arrepiava-me pensando nisso. Achava-me ali diante de criaturas supliciadas e, consequentemente, envilecidas. A minha educação estúpida não admitia que um ser humano fosse batido e pudesse conservar qualquer vestígio de dignidade. Tiros, punhaladas, bem: se a vítima conseguia restabelecer-se, era razoável andar de cabeça erguida e até afetar certo orgulho: o perigo vencido, o médico, a farmácia, as vigílias de algum modo a nobilitavam. Mas surra - santo Deus! - era a degradação irremediável. Lembrava o eito, a senzala, o tronco, o feitor, o capitão de mato. ${ }^{17}$
\end{abstract}

O narrador, após relembrar os fatos, reconstitui a repercussão deles na sua interioridade e passa a refletir sobre isso, resgatando o seu próprio passado de maneira confessional18. $\mathrm{Na}$ óptica dessa subjetividade e como resultado da sua vivência, a surra era uma maneira de "destruir a dignidade de um indivíduo". O arrepio então resulta do contato com algo já conhecido, vivido e observado.

A menção à tortura reativa no narrador o seu passado rural, as raízes de uma infância marcada por castigos e praticada por seus superiores, dirigida a ele e aos outros, e destinada à manutenção da normalidade social em um país recém-saído da escravidão. Dentro desse universo rural, que ressurge presentificado (indicando a não-superação do legado social e moral), a violência sistêmica também fabricava os seus heróis, o que dá a medida do "código do sertão" e das formas de sociabilidade do lugar. A alusão à surra, porém, porque recuperada pelo narrador no fluxo da rememoração, atravessa a história e cristaliza, na interioridade do sujeito, imagens da escravidão e da Colônia, no revolver de um passado que ressurge abruptamente e que o detento considerava, de certo modo, restrito à região de que provinha. As imagens que convocam o regime escravista em suas manifestações mais brutais materializam- 
se para espanto e perplexidade do narrador, e a interjeição ("Santo Deus"!) resgata a surpresa de quem deparou com a atualidade de formas arcaicas de opressão. A modernização enfim mostrava o seu reverso cruel, na manutenção e reposição, como estratégia de Estado, das relações de matriz escravista nos centros urbanos e em lugares supostamente mais "desenvolvidos" como o Sul do país (no Pavilhão dos Primários a tortura será rotineiramente percebida pelo detento). A reflexão do narrador sobre a tortura o faz pensar nos pequenos ladrões de sua terra, rigorosamente punidos:

\begin{abstract}
Está visto que não se punem os grandes atentados, mais ou menos legais, origem das fortunas indispensáveis à ordem, mas os pequenos delinquentes sangram nos interrogatórios bárbaros e nunca mais se reabilitam. Não me ocorrera a ideia de que prisioneiros políticos fossem tratados da mesma forma: a palavra oficial dizia o contrário, referia-se a doçura, e não me achava longe de admitir pelo menos uma parte disso. Um jornalista famoso asseverava que os homens detidos no Pedro I bebiam champanhe. Com certeza na doçura e no champanhe havia exagero; não me viera, contudo, a suspeita de que a imprensa e o governo mentissem descaradamente quando isto não era preciso ${ }^{19}$.
\end{abstract}

O mergulho na própria experiência mostra que os grandes ladrões não apenas saem ilesos dos crimes, mas são necessários para garantir a "ordem" latifundiária. Nesse contexto, o Estado nada mais é do que um instrumento de defesa da propriedade, uma arma dos ricos contra os pobres ${ }^{20}$. A ironia do narrador ("está visto que não se punem os grandes atentados, mais ou menos legais"), ao apresentar como obviedade o que é resultante da dominação econômica, revela o seu conhecimento acerca da forma bárbara de acumulação capitalista no Brasil, processo truculento e brutal que inclui não apenas a violação da lei, mas a sua instrumentalização contra o mais pobre e sempre em defesa da propriedade ${ }^{21}$. Já os ladrões miúdos são punidos, espancados e para sempre ficam estigmatizados: a herança escravocrata atualiza o açoite. Essa "tatuagem na alma" que estigmatiza os ladrões miúdos com a marca dos escravos fugidos de algum modo também assinalaria o protagonista a partir de então, como prisioneiro político que era.

Tal constatação entra em conflito com o que era propalado pelos órgãos oficiais e pela imprensa, notadamente empenhada, juntamente com o governo Vargas, em expurgar do país o "perigo vermelho", construindo mentiras absurdas a fim de granjear apoio público para a sua política. Para o narrador, porém, não era preciso fabricá-las, possivelmente porque ele percebia, desde a prisão, que Vargas detinha o apoio franco das massas.

A partir da cadeia, a percepção da equalização entre militância e criminalidade lhe dá a possibilidade de corrigir a óptica pela qual via as relações de poder, a justiça e a imprensa corrompida: a imagem oficial do "país doce", da qual o prisioneiro já desconfiava, desmorona ante o que ele vê e ouve no porão do navio, quando tem acesso efetivo aos mecanismos de funcionamento do Estado repressor:

\footnotetext{
Habituara-me de fato, desde a infância, a presenciar violências, mas invariavelmente elas recaíam em sujeitos da classe baixa. Não se concebia que negociantes e funcionários recebessem os tratos dispensados antigamente aos escravos e agora aos patifes miúdos. E estávamos ali, encurralados naquela imundície, tipos da pequenaburguesia, operários, de mistura com vagabundos e escroques. E um dos chefes da sedição apanhara tanto que lá ficara em Natal, desconjuntando, urinando sangue. ${ }^{22}$
}

A violência com a qual esse narrador conviveu era dirigida normalmente às classes baixas, e de algum modo ele participara dessa realidade, em que os pobres sofriam os castigos 
antes destinados aos escravos. Nesse sentido, o capítulo "O moleque José", de Infância, pode ser considerado emblemático por ilustrar a familiaridade do menino com a violência e o substrato escravista. A família do protagonista possui vários agregados, filhos da negra Luísa, dentre eles José, castigado sempre que o pai passava por dificuldades no comércio, quando se assemelhava a "uma insignificante mancha trêmula". Ao levar chicotadas por uma traquinagem, José emite um "doloroso ganido de cachorro novo", e o menino decide então torturar também o agregado:

Retirei uma acha curta do feixe molhado, encostei-a de manso a uma das solas que se
moviam por cima da minha cabeça. Na verdade apenas toquei a pele do negrinho. [...]
Com certeza José nada sentiu. Cobrei ânimo, cheguei-lhe novamente ao pé o
inofensivo pau de lenha. Nesse ponto ele berrou com desespero, a dizer que eu o
tinha ferido. Meu pai abandonou-o. E, vendo-me armado, nem olhou o ferimento:
levantou-me pelas orelhas e concluiu a punição transferindo para mim todas as culpas
do moleque. Fui obrigado a participar do sofrimento alheio. ${ }^{23}$

Nesse capítulo de Infância fica clara a passagem, do menino protagonista, de observador a algoz e, também, à vítima da tortura, revelando o circuito opressor alimentado por uma realidade social cuja dinâmica remonta à escravidão. Algo dessa operação, inclusive a inversão de papéis (em contexto diverso), ocorre nas Memórias: para o narrador, o açoite destinado às classes baixas não produzia estranhamento; o atípico, agora, é que classes mais altas também sofressem os castigos. A sua surpresa não decorre, então, da ciência quanto ao processo de acumulação assentado na violência física, mas na descoberta de que, na passagem da República Velha à Nova, formas arcaicas de coerção e mando eram realimentadas e ampliadas aos setores médios pela lógica histérica de "combate ao comunismo" 24.

Há certamente uma componente classista no fato de o narrador afirma ter recusado o tratamento dispensado aos ladrões e aos escravos. Mas há, também, a autoexposição de uma formação calcada nessa mesma conduta discriminatória, que, longe de dissimular, desvela a autocrítica feroz de um sujeito que tentava não se igualar à escória por trazer, em si, marcas de uma diferenciação social que o Estado tratava de abolir. A formulação irônica apresenta uma concepção pessoal que soa como verdade geral, mas que termina desacreditada, pois a cadeia revelava-lhe o "inconcebível", na explicitação crua do terror obscurantista em que o país estava inserido. De certo modo, acusar a prevalência das formas arcaicas de sociabilidade é para esse narrador, também acusar dolorosamente a si próprio, como se a transição para a Nova República encontrasse eco na subjetividade que narra, encena e denuncia uma reação pessoal que remete ao passado e ao universo oligárquico que tanto o marcou.

Por isso, a repressão promove um rebaixamento doloroso, a princípio incompatível com o então funcionário público e simpatizante comunista; logo, porém, ele percebia que a vida no funcionalismo não o distinguia das demais criaturas supliciadas. Assim, o passado ressurge em forma de espectro, ainda mais temível e cruel, porque antes o que o atingia de modo indireto ou caseiro poderia, enfim, vir ao seu encontro de modo franco, ubíquo - e oficial ${ }^{25}$.

Esse temor ajuda a entender a referida "imundície" do navio evitada pelo prisioneiro, na qual ele se vê "encurralado", uma alusão à presença de marginais no porão. Trata-se de rejeitar a mistura com os "vagabundos e escroques" na mesma proporção que as forças repressivas trabalhavam para igualá-los. Ao resistir contra a própria degradação, ele tenta, de algum modo, impor-se por meio da recusa ao nivelamento. Como consequência, surge no excerto não 
apenas uma feição de classe, perceptível na associação que o narrador faz entre a ralé e a sujeira do Manaus, como também a (auto) denúncia do seu comportamento discriminatório em relação aos pobres.

A passagem se encerra com nova referência ao fato que gerou a reflexão: " $E$ um dos chefes da sedição apanhara tanto que lá ficara em Natal, desconjuntado, urinando sangue". É como se, depois de repisar o mote e compreendê-lo na sua amplitude, explicitando a verdade de um país que adentrava a modernidade por meio da reposição do atraso cristalizada nos rituais de violência corpórea direta, o narrador voltasse ao motivo que suscitou sua interiorização reflexiva, transformado pela descoberta que ela the proporcionou: o olhar para os revoltosos espancados não seria mais o mesmo, porque ele saberia, a partir de então, que a repressão e os castigos também o incluiriam como alvo.

O mergulho na subjetividade permite ao narrador elucidar, a posteriori, a realidade para a qual foi compulsoriamente impelido, e que lhe deu acesso ao Brasil não revelado às massas nem veiculado pelos órgãos de opinião. Assim esse sujeito tem condições de perceber, com bastante perplexidade e espanto, que o nexo colonial de algum modo se atualizava e era incorporado pelo Estado moderno como normalidade, como regra geral de seu funcionamento, sem nenhum subterfúgio.

Os vínculos da sociabilidade colonial repostos pelo desenvolvimento das forças produtivas, que o narrador militante faz questão de ressaltar ao reviver a sua experiência de prisioneiro, contrariam também a concepção etapista do processo histórico encampada pelo PCB desde os anos 1920, como projeto político da Internacional Comunista (IC) para os países "coloniais, semicoloniais e dependentes" como o Brasil. Segundo essa teoria, a superação dos "restos feudais" nesses países seria possível apenas por meio de uma revolução burguesa (ou seja, mediante o pleno desenvolvimento do capitalismo), a qual forneceria então as condições para que, em futuro indefinido, ocorresse a revolução proletária - uma cabal subordinação do Movimento Comunista Internacional aos interesses da política externa do Estado soviético. $\mathrm{O}$ posicionamento do narrador nesta cena, ao mostrar um passado que se revigora em virtude do capital, entra em choque com a visão linear do processo histórico adotada pelo $\mathrm{PCB}$, revelando a superficialidade nas análises das contradições internas dos países periféricos feitas pela IC, o que amplifica a discussão político-partidária inserida neste tecido de memória ${ }^{26}$.

No plano da trama, a ilusão da personagem sobre a prisão (entendida no início das Memórias como uma "libertação", como possibilidade de se mudar para o Sul do país e de se profissionalizar, definitivamente, como escritor) começa a ruir nesta primeira parte do livro, quando o detento repentinamente percebe ser o seu encarceramento uma sentença de culpa não formalizada, pairando kafkianamente como sombra. Se a recusa ao nivelamento revela um traço de classe, ela é, também, uma forma de sobrevivência: era preciso não se despersonalizar por completo e reagir à agressão compulsória da prisão. Para o narrador, fechar-se sobre si e tentar compreender o seu lugar social, bem como as heranças ideológicas de que ele também guarda o legado, é o modo de não apenas entender o passado, mas principalmente tomar partido na luta política que o absorve.

A figuração da subjetividade familiarizada com o passado rural-escravista e capturada no momento em que esse mesmo passado retorna renovado e sobre ela desaba revela de maneira bastante contundente o processo de modernização do país em suas mais amplas 
contradições, na reativação do que parecia estar superado, e também na descoberta da extensão da barbárie, antes "privilégio" dos pobres e dos escravos ${ }^{27}$.

Assim, é possível, por meio da análise deste excerto das Memórias, detalhar o movimento da composição do livro, que, como vimos, consiste no relato factual somado à crispação do narrador. Tal movimento se materializa em um discurso analítico, confessional e reflexivo, que irrompe como sequência de um núcleo episódico: uma confissão, que inclui, muitas vezes, um exame de consciência de classe. Como definiu Antonio Candido, Graciliano, inserido no quadro dos romancistas de 1930, opta por fazer "uma análise impiedosa" da pequena-burguesia, assim como Octavio de Faria, em espectro ideológico oposto, fez em relação à grande ${ }^{28}$.

Nas Memórias ele amplia tal projeto, por analisar impiedosamente a si próprio (e, evidentemente, a sua classe), com vistas à discussão política e ao seu posicionamento na luta comunista. Por esse motivo, as Memórias do cárcere não podem ser consideradas como mais um exercício de cinismo das classes dominantes, como se nota no Memorial de Aires, nem possuem o apelo a um supostamente portentoso passado colonial que caracteriza alguns ensaios interpretativos de feição memorialista, como Casa-grande \& senzala, de Gilberto Freyre $^{29}$. A herança escravista e a ordem patriarcal ressurgem, para o narrador das Memórias, materializadas no horror ante a política do Estado dos anos 1930 e 1940, o que, por contrariar também posições historicamente encampadas pelo $\mathrm{PCB}$, dá a medida do debate político que a obra propõe. Nesse sentido, o livro, ao formalizar os posicionamentos do artista militante por meio da composição sugere, ao seu modo, também uma interpretação do país, na esteira dos ensaios de 1930, com os quais a literatura de Graciliano guarda evidente intimidade.

Literariamente, as Memórias mostram que a retirada compulsória da personagem da lógica dos dias expõe uma subjetividade a princípio alienada, mas que, por meio do distanciamento imposto pela prisão e pela decalagem temporal entre o acontecido e o narrado, permite ao narrador revelar a consciência dessa alienação e a reformulação de suas percepções como parte de um momento de crítica ou de tentativa de superá-las, quando entra em cena, de forma infusa, o olhar do militante, por meio do discurso indireto livre. Cabe ressaltar que para Pasolini esse recurso, traduzido para o cinema como a "subjetiva indireta livre", não se define apenas pela simpatia entre autor e personagem (ou entre o sujeito do passado e o do presente), mas também pela iluminação de aspectos "odiosos e essenciais" de uma voz narrativa em relação a outra ${ }^{30}$. Dessa maneira, fica claro que o mundo narrado na obra contém as marcas de autocrítica e engajamento do narrador situado entre os anos 1940 e 1950: este o prisma que se torna a condição de existência, e de força, do livro.

Portanto nas Memórias do cárcere, como nas obras ficcionais, o ponto de vista estético fixa-se no resultado literário e se liberta das intenções do autor, o que permite a apreensão de uma dinâmica histórica que não se limita ao âmbito da ficção ou do simples registro. A representação de impasses estruturais da sociedade brasileira, que se revelam inclusive na consciência do narrador, dá a medida do teor de verdade dessa narrativa de gênero híbrido que, em uma primeira e árida leitura, pode parecer tão somente um "resgate do passado". Salvo erro, estamos no melhor terreno da tradição realista, capaz de intuir e desdobrar literariamente o dinamismo profundo da vida social e política sob o capitalismo e de, sobretudo, lutar contra ela - ainda que, para isso, o escritor tenha de exibir sem pudores a si e ao seu passado. 


\section{Notas de fim}

${ }^{1}$ Antonio Candido. Op. cit. Rio de Janeiro: Ouro sobre Azul, 2006.

2 Álvaro Lins. "Valores e misérias das vidas secas"; Otto Maria Carpeaux, "Visão de Graciliano Ramos". In: José Carlos Garbuglio et al. Graciliano Ramos: antologia e estudos. São Paulo: Ática, 1987, pp. 261-269 e 243-248.

${ }^{3}$ Georges Gursdorf. Les écritures du moi: lignes de vie I. Paris: Odile Jacob, 1991.

${ }^{4}$ Max Weber. "Os fundamentos da ascese intramundana". In: A ética protestante e o "espírito" do capitalismo. São Paulo: Companhia das Letras, 2011, pp. 112-113.

5 Cf. José Aderaldo Castelo. "Produção literária do romantismo de época". In: A literatura brasileira: origens e unidade: 1500-1960 (vol. I). São Paulo: Edusp, 1999, pp. 252-257.

${ }^{6}$ Roberto Schwarz. “Aquele rapaz”. In: Sequencias brasileiras. São Paulo: Companhia das Letras, 1999, p. 191.

7 Antonio Candido. "Prefácio inútil”. In: Textos de intervenção. São Paulo: Duas Cidades; Editora 34, 2002 , p. 194-195.

${ }^{8}$ Cf. Jorge Luiz Ferreira. "Confessar os pecados e expulsar os demônios". In: Prisioneiros do mito: cultura e imaginário político dos comunistas no Brasil (1930-1956). Rio de Janeiro: Eduff, 2002, p. 130.

9 György Lukács. "A físionomia intelectual dos personagens artísticos”. In: Marxismo e teoria da literatura. São Paulo: Expressão Popular, 2010, p. 196.

${ }^{10}$ Memórias do cárcere, "Viagens". Rio de Janeiro, São Paulo: Record, 1986, p. 141.

${ }^{11}$ No dia 23 de novembro de 1935, sargentos, cabos e soldados do $21^{\circ}$ Batalhão de Caçadores de Natal, dirigidos pelo Partido Comunista local, dominaram a cidade e instauraram o Governo Revolucionário Popular que destituiu o governador do Estado, requisitou numerário no Banco do Brasil e resistiu por quatro dias, estendendo seu domínio para o interior do Rio Grande do Norte. Isolado (dias depois, os movimentos no Recife e no Rio de Janeiro também seriam sufocados), o motim passou da euforia inicial à rápida derrocada. Sobre o apoio da Internacional Comunista ao levante nas três capitais, ver John Dulles. "As insurreições de 1935". In: Anarquistas e comunistas no Brasil. Rio de Janeiro: Nova Fronteira, 1977, p. 424.

12 Marly Vianna afirma que a direção do PCB reconheceu a derrota, mas não os seus erros, uma vez que vários quadros se haviam revelado, a revolução ficara na ordem do dia, o movimento continuava no interior do Nordeste e, pela primeira vez, o PCB participara de uma luta armada aliando forças. In: Revolucionários de 1935-sonho e realidade. São Paulo: Expressão Popular, 2007, pp. 373-374.

13 Cf.Thomas Skidmore. In: Brasil: de Getúlio a Castelo. São Paulo: Paz e Terra, 2007, pp. 32-54. ${ }^{14}$ A percepcão da ofensiva do Estado contra os trabalhadores também não escapou ao olhar de Mário de Andrade no conto "Primeiro de Maio", conforme a análise de Iná Camargo Costa. A "ratoeira" montada pela polícia no Palácio das Indústrias, onde seria "celebrado" (e não comemorado) oficialmente o feriado é percebida a tempo pelo protagonista 35, um carregador de malas da Estação da Luz e provável área de influência do Partido ("Mário de Andrade e o primeiro de Maio de 35”. In: Trans/form/ação: Revista de Filosofia. São Paulo, v. 18, 1995, pp. 2942).

15 A repressão mais brutal no levante potiguar recaiu sobre os civis, todos militantes e líderes do Partido na região: Lauro Lago, José Macedo e João Batista Galvão (a quem alude veladamente o narrador das Memórias). Este último foi capturado juntamente com Lauro Lago e José Macedo. Espancado pela polícia, passou dezoito meses na Casa de Detenção de Natal e perdeu um rim em virtude dos maus-tratos recebidos (Cf. Lauro Gonzaga Cortez. A Revolta comunista de 1935 em Natal. Natal: Cooperativa Cultural do Rio Grande do Norte, 2005). 16 "Brasil: cultura e identidade". In: Por um novo Machado de Assis. São Paulo: Companhia das Letras, 2006, p.379.

${ }^{17}$ Op. cit., p. 141.

18 Sobre este aspecto da composição das Memórias, escreve João Luiz Lafetá: “fica claro para o leitor que há uma tentativa constante do autor em compreender aquela situação que está vivendo, de tirar uma espécie de moral da história, uma ética. Em suma, discutır o comportamento pessoal dos presos, o comportamento das classes sociais de acordo com seus interesses. Isso dá ao livro um tom acentuadamente intelectual" ("O Porão do Manaus". In: Flávio Aguiar e outros. Gêneros de fronteira: cruzamentos entre o histórico e o literário. São Paulo: Xamã, 1997, p. 230).

${ }^{19}$ Op. cit., p. 142.

20 Com a palavra, o pai do liberalismo, Adam Smith, em 1776: "Instituído em princípio para a segurança da propriedade, o governo civil é, na realidade, instituído para a defesa dos ricos contra pobres, ou dos que têm propriedade contra os que não têm nenhuma" (In: A Riqueza das Nações. São Paulo: Martins Fontes, $2003, \mathrm{p}$. 906). No século XX, Walter Benjamin, ao discutir as relações entre o direito e a violência na sociedade alemã após a Revolucão de 1918, revelou como a violência é, a um tempo, fundadora e conservadora do direito institucionalizado, sendo o Estado o único elemento social que dela pode dispor legitimamente e em nome de seus interesses particulares, contando para isso com o poder militar e o poder da policia ("Crítica da violência crítica do poder". In: Documentos de cultura, documentos de barbárie (textos escolhidos). São Paulo: Cultrix, 1986, pp. 160-175).

${ }^{21}$ Nesse sentido, Paulo Honório parece ser, na obra de Graciliano, o emblema desse processo. Ele persegue o capital "sem descanso", efetua transač̃es comerciais "de armas engatilhadas" e assassina o vizinho Mendonça a fim de aumentar a extensão de suas terras e, consequentemente, a produção. (S. Bernardo. Rio de Janeiro, São Paulo: Record, 2004, capítulos III e VI).

22 Op. cit., p. 142.

${ }^{23}$ Op. cit., pp. 90-91. 
${ }^{24}$ Ver, a respeito, Rodrigo Patto Sá Motta. “A primeira grande onda anticomunista: 1935-1937”. In: Em guarda contra o perigo vermelho: o anticomunismo no Brasil (1917-1964). São Paulo: Perspectiva, 2002, pp. $179-230$.

25 Dito de outro modo, o prisioneiro descobria que a passagem para a modernidade no Brasil continuava a referendar as relações domésticas e os contatos primários como o "modelo obrigatório de qualquer composição social entre nós", em que triunfa "o geral sobre o particular, o intelectual sobre o material e o abstrato sobre o corporeo" (Cf. Sergio Buarque de Holanda. "O homem cordial". In: Raizes do Brasil. São Paulo: Companhia das Letras, 2003, p. 141). Como se vê, o emprego de recursos estilísticos que priorizam os danos infligidos ao corpo na cena, não deixa muitas dúvidas sobre o perfil do nosso Estado Moderno.

${ }^{26}$ A respeito da política da Internacional Comunista para os países como o Brasil e de como ela foi assimilada pelo PCB, ver o estudo de Paulo Sérgio Pinheiro, Estratégias da ilusão: a revolução mundial e o Brasil, 19221935. São Paulo: Companhia das Letras, 1991.

27 Conforme sintetiza Francisco de Oliveira, a passagem para a ordem industrial implementada por Vargas representa uma tentativa de expulsar o custo do escravo do custo da producão, dentro de um modelo econômico cuja progressão não requereu a destruição completa do antigo modo de acumulação (In: Crítica à razão dualistalO

ornitorrinco. São Paulo: Boitempo, 2003)

28 "Poesia, documento e história". In: Brigada ligeira. Rio de Janeiro: Ouro sobre Azul, 2003, p. 43.

29 Para uma avaliação dessa componente saudosista em Casa-grande \& senzala em contraponto a Raízes do Brasil, ver Antonio Candido, "A visão política de Sérgio Buarque de Holanda". Folha de S. Paulo, 25 jan. 1998. 30 Pier Paolo Pasolini. "Intervenção sobre o discurso indireto livre". In: Empirismo hereje. Lisboa: Assírio Alvim, 2010. 